NUDGING INTO SUBJECTIFICATION: GOVERNMENTALITY AND PSYCHOMETRICS

John Cromby \& Martin E.H.Willis

Critical Social Policy (2013)

DOI: $10.1177 / 0261018313500868$

Numbers in square brackets [p.xx] refer to page numbers in the published version.

CONTACT:

Dr. J Cromby

Psychology, SSEHS

Loughborough University

Loughborough, Leics

LE11 3TU England UK

J.Cromby@lboro.ac.uk 


\title{
[p.1]NUDGING INTO SUBJECTIFICATION: GOVERNMENTALITY AND PSYCHOMETRICS
}

\begin{abstract}
The current age of 'austerity' is associated with neoliberal ideology. Neoliberalism can be understood as a form of governmentality - a way of reconfiguring selves and the social order in accord with the demands of market economies. A recent UK policy initiative by the Coalition government's Behavioural Insights Team required benefits claimants to submit to online psychometric testing. We examine this policy in some detail, arguing that this use of psychometric testing is flawed, unethical, and unlikely to help claimants to find work. Our analysis of the test procedure and its results suggests that the policy functions primarily as a means whereby benefit claimants can be 'nudged' towards acceptance of the precepts of neoliberal subjectivities.
\end{abstract}

\section{Introduction}

The financial crisis of 2007-8 helped to usher in an age of 'austerity' across the USA and Western Europe, including the UK. Clarke and Newman (2012) [p.2] describe how the responsibility for massive debts incurred by an under-regulated financial sector has been transferred by these governments to a supposedly profligate public sector, characterising this and other aspects of the present moment as a kind of magical thinking. Their analysis identifies how, because unemployment tends to make apparent the many links between inequality and various social problems, during such economic retrenchments "worklessness is typically named as a problem of 'character'" (Clarke and Newman, 2012 p.311). This observation may help to explain why the news that jobseekers in England were being required to submit to online psychometric testing, which first appeared on a relatively obscure blog in mid-April 2013 (skwalker1964, 2013), was rapidly picked up by mainstream media and became the focus of widespread discussion.

The blog provided evidence demonstrating that claimants were receiving letters requiring them to complete an online test (amongst other tasks) to very short deadlines, and threatening that "Failure to comply may result in loss of benefits". The test was a version of the Values in Action (VIA) 'Inventory of Signature Strengths', an assessment of personality or character (available at: http://www.behaviourlibrary.com/strengths.php). The blog claimed (and we found) that the test initially gave a result even if no answers were ticked; this was corrected once the story entered the mainstream media. As the story developed it emerged that the suggestion that benefit claimants should take this test was a policy initiative devised by the UK government's Behavioural Insight Team (BIT), and ethical and scientific concerns were aired. Then, early in May, it was revealed that VIA had previously refused BIT permission to use the test because "They are using the non-validated version ... we had tested it a while back and it failed". Although VIA did not attempt to challenge or refute this claim (which was based on correspondence seen by a journalist), in a further development they later informed the Guardian that "Any misunderstandings that may have occurred between VIA and the Behavioural Insights Team have been resolved at this point" (Malik, 2013).

In what follows we assess this policy initiative with respect to neoliberal ideology, suggesting that it might function to influence the subjectivities of benefit claimants in accord with neoliberal precepts. 
Neoliberalism is a loosely-defined capitalist ideology that informs the policies of many contemporary Western governments, positioning citizens primarily as entrepreneurs and consumers and presenting domination of the public sphere by the 'free' market as a natural accomplishment (Brown, 2006). Neoliberal policies emphasise tropes such as free market efficiencies, privatisation and choice; promote activities of entrepreneurship and self-care; and highlight personal qualities of responsibility, self-determination, moral autonomy, adaptiveness and flexibility (e.g. Fyson \& Cromby, 2012). Peck and Tickell (2002) observe that the effects of neoliberalism are always local and specific, reflective also of other (ideological, temporal, spatial) influences with which it intersects: our [p.3] focus on one particular policy initiative is therefore appropriate. With respect to subjectivity, Foucault (2008) argued that rather than govern by dictating rights and responsibilities, neoliberalism proceeds by harnessing desires for independence and creativity to the interests of business, reconfiguring workers as entrepreneurs of their own skills and abilities, and reconfiguring the social relations of capitalism to emphasise competition, not between workers and capitalists, but between workers themselves. Rather than being entirely new, in some respects this reconfiguration represents an extension of existing trends within liberalism, an expansion or intensification of regulation (Papadopoulos, 2003): hence, the neoliberal emphasis on qualities such as personal responsibility and adaptiveness is already somewhat familiar.

Whilst the influence of neoliberalism on UK policies on welfare and benefits can be traced back at least to the prior New Labour administration (Prideaux, 2010), these policies seem to have acquired a particular character under the 'austerity' regime of the current Coalition. Wiggan's (2012) discourse analysis of policy documents found that three interlocking themes are now discernible: that the country is 'racked by worklessness'; that there is a culture of dependency that discourages people from taking up available work; and that current initiatives which emphasise economic rationality and intensify the punitive aspects of the benefit system are necessary reforms. Notwithstanding that policy documents occasionally acknowledge some of the financial constraints and institutional barriers facing those on benefits and low-incomes, their overall tone serves to attribute responsibility for poverty and unemployment to the poor choices and unhelpful behaviour of individuals. In conjunction with widely-reported ministerial speeches engineering a (spurious Coote and Lyall, 2013) distinction between 'strivers' (those in work) and 'skivers' (those on benefits), and reinforced by frequent media portrayals of 'benefit scroungers' (Mulheirn, 2013), these policies provide the immediate backdrop to BIT's initiative and its implementation by benefits agency staff.

The work of BIT is informed by a blend of disciplines including neuroscience, behavioural psychology and economics, a mixture known collectively as behavioural economics and known informally (after a book popularising the approach) as 'nudge' (Thaler and Sunstein, 2009). Behavioural economics recognises that human decisions are neither simply conscious and rational, nor entirely random: rather, decisions are systematically influenced by 'choice architectures', subtle environmental prompts that produce 'arbitrary coherence', in part through the influence of earlier choices or 'imprinting'. Behavioural economics endorses libertarian paternalism: the notion that ostensibly free choices can legitimately be subtly influenced in the directions favoured by policymakers, provided that their policies have prior public consent. Whilst this doctrine might appear relatively harmless in relation to BIT initiatives such as promoting loft insulation or reducing road traffic accidents, [p.4] it is likely to prove more controversial in other policy contexts. Although BIT is new, Whitehead et al., (2011) show that the influence of behavioural economics upon government can be traced back to 2001 , and that - despite its ostensive political neutrality - its policy implementation is typically 
ideologically influenced. They also find that policies frequently presume normative understandings of rationality that behavioural economic theories refute - for example, by associating emotionallyinfluenced decision-making with particular (often, disadvantaged) groups, rather than with humans in general. They conclude that behavioural economics potentially "enables policy makers (and an emerging cartel of psychocrats) to foreclose discussion of what the values associated with 'good behaviour' should be" (Whitehead et al., 2011 p.2834, italics in original).

Whilst this policy initiative was devised by BIT, the VIA test it deploys is a product of positive psychology: a relatively new, US-led sub-discipline of psychology focused specifically upon 'positive' institutions, emotions and traits (as opposed to identifying adaptive functioning by derivation from, or contrast with, difficulties and defects). Positive psychology is shaped by influences that include (multiple variants of) Christianity and corporate practices of motivational speaking (Ehrenreich, 2009), and advocates argue that it is distinctive both in its focus on the positive and in its use of scientific methods to refine and test its claims (Seligman, 2003). The VIA test is derived from a detailed taxonomy of character strengths and virtues that was produced by positive psychologists and is sometimes described as the scientific backbone of the approach (Peterson and Seligman, 2004).

Positive psychology influenced UK policy under the New Labour administration of Prime Minister Blair, primarily through the work of 'Happiness Tsar' Lord Layard and the establishment of the IAPT (Improving Access to Psychological Therapies) programme. However, despite some laudable aspirations, and despite also capturing elements of the popular imagination (albeit with the assistance of very generous funding and marketing consultants - Yen, 2010; Ehrenreich, 2009), it remains somewhat marginal within the wider discipline and is sometimes a focus of critique. Becker and Marecek (2008) show how, despite its claims to cultural universality, positive psychology depends upon a Western notion of the bounded, autonomous self; that it endorses the 'American Dream' that wealth and success are equally available to everyone; that it takes a selective view of 'positive' institutions (for example, by approving of churches but ignoring trades unions); and that it largely ignores the power relations (of class, gender and ethnicity) that structure capitalist societies. Held (2005) interrogates positive psychology's purported scientific status, arguing that it promulgates a 'double epistemic standard': although it claims to be value neutral and empirically driven, it is consistently biased toward optimistic discourses and positions. Other concerns include the impossibility of defining 'positive' emotions, institutions and traits in [p.5] a context-free manner, and the conceptual, epistemic and methodological issues associated with attempts to do so (e.g. (Christopher and Hickinbottom, 2008; Slife and Richardson, 2008) .

Policy toward benefit claimants is but one aspect of wider policies on welfare, and the relations between welfare policy and psychology were explored by Stenner and Taylor (2008). Their analysis of changes in the way that welfare is configured and understood emphasises how psychology can readily be associated with social processes of individualisation and subjectification. Sketching the recent history of welfare states, they demonstrate an increasing trend toward an "amplification of the social relevance of what can loosely be called the 'psychological' dimension" (Stenner and Taylor, 2008 p.420), and suggest that this is unsurprising since "The more the weight of welfare provision becomes a matter of individual responsibility, choice and desire, the more prominent and unavoidable the psychological dimension becomes" (Stenner and Taylor, 2008 p.421). In what follows, then, we focus upon the psychological aspects of the BIT initiative: how psychology is being 
used to legitimate policy, and how policy might function psychologically in relation to the neoliberal agenda of which it is an element. In particular, we are concerned with the policy implications of how the VIA test is being presented as an objective, scientific instrument that meaningfully and accurately measures the 'signature strengths' of benefit claimants. The test's apparent objectivity depends for its credibility upon psychometrics, the practice of measuring psychological operations, capacities and qualities: accordingly, we first provide a critical discussion of psychometrics; we then consider the VIA test itself.

\section{Psychometrics}

In the right context, psychometric testing is useful and warranted - for example, in the identification of specific cognitive impairments, neurological impairments and special educational needs. Here, however, our focus is upon self-report measures of personality or character traits, including the VIA test, rather than upon psychometric testing in general. There are multiple, interlocking issues associated with personality psychometrics that raise questions about the objectivity and utility of such tests, and hence about their adequacy as instruments of policy. We begin by briefly considering four concerns - construct validity, reliability, participant reactivity, and response bias - that are widely acknowledged by psychometricians themselves. We then consider introspection, upon which self-reports rely; we discuss the fundamental question of whether psychological attributes such as personality are actually quantifiable; and finally, we briefly consider the importance of personal meaning and interpretation.[p.6]

When devising new tests, both reliability and construct validity are fundamental concerns for psychometricians. Reliability refers to how consistent a test is over time: a reliable personality assessment should, in principle, produce a very similar score each time an individual takes the test (Robins et al., 2007). Construct validity refers to whether or not the test measures the theoretical construct it is intended to measure, as opposed to inadvertently measuring something else (Jackson, 2012): for example, whether the VIA test really is identifying 'signature strengths' embedded within the personalities of those who complete it. Psychometricians use statistical analyses to help them assess reliability and validity, and inevitably some versions of their tests fail to meet adequate standards. As previously mentioned, the VIA test seems to have failed validity testing: if this claim is correct, it cannot legitimately be said to be measuring 'signature strengths'.

Because measures of character or personality such as the VIA test depend upon self-report questionnaires they are especially prone to problems of participant reactivity and response bias. Participant reactivity describes how individuals alter their performance or behaviour due to the awareness that they are being observed (Jackson, 2012). Probably the most common form of reactivity is a response bias known as social desirability responding: the tendency of respondents to answer questions in a manner that (they imagine) will be viewed favourably by others (Weiten, 2010). AUTHOR (2011) argued that this bias is also relevant to another recent policy initiative, the Coalition government's implementation of measures of national wellbeing, since there is good evidence (from the government's own surveys) that social desirability significantly influences responses to wellbeing questionnaires. Other substantive topics where social desirability responding is known to be especially likely include sexual behaviour, drug use, abilities, and personality (Rust and Golombok, 1999), suggesting that the VIA test is also particularly likely to be vulnerable to this kind of bias - a consideration which might in fact help explain its purported lack of validity. 
Of course, it is possible that the media reports of VIA's statement about the test's validity are incorrect or out of date. Nevertheless, there are further reasons to be concerned about tests of this kind. Like many psychometric instruments the VIA test necessarily depends upon introspection: the belief that people have privileged knowledge of their own psychology, such that they can look 'inside' themselves and correctly report what they see there. The VIA test consists of forty-eight items with a diverse range of prompts, including "I tend to make snap judgments" (question 6), "I voluntarily helped a neighbour last month" (question 19) and "I always look on bright side (sic)" (question 39). Participants are asked to rate themselves against each item using a 5-point Likert scale ranging from 'very much like me' to 'very much unlike me' - to introspect, or look inside themselves, and then report the extent to which each statement applies to them. However, the accuracy and [p.7] reliability of introspection have been debated since the earliest days of psychology (Danziger, 1994). Historians have described how trained introspectors, reporting upon objectively quantifiable psycho-physiological stimuli (e.g. the number of light pin-pricks on the back of a hand), were still unable to achieve acceptable levels of reliability. This problem is likely to apply with even more force to attributes and experiences such as those tapped by the prompts in the VIA test, which are on the one hand more context-bound and situation dependent, and on the other hand more amorphous and insubstantial. Moreover, it is well established in psychology that there are many aspects of ourselves and our activity of which we are largely unaware or to which we simply do not have introspective access (Kahneman and Tversky, 1982), and there is corresponding evidence that thinking too much about why we feel as we do about something can actually confound our understanding (Wilson and Hodges, 1992). Indeed, it may be recalled that these kinds of limitations upon human insight and conscious regulation are actually key presumptions of behavioural economics, which locates decision-making just as much in un-noticed features of the environment (choice architectures) or the un-recalled past (imprinting) as in those psychological capacities and experiences available to conscious introspection. Thus, there is a contradiction here: the psychological assumptions of the BIT policy are incompatible with those made by the tool it has chosen to implement this policy.

The VIA test can also be questioned on more fundamental grounds. Michell $(2000,2008)$ suggests that even though it is widely accepted within the discipline that psychological attributes are quantitative - and therefore intrinsically measurable - this assumption has never been directly tested. Michell argues that psychometricians must first demonstrate that psychological attributes (such as 'curiosity' - see Table 1) are quantitative, rather than qualitative, before developing measuring instruments (see also Essex and Smythe, 1999). He demonstrates that psychometricians have tended to avoid this issue by adopting an anomalous definition of measurement as "the assignment of numerals to objects or events according to rule" (Michell, 2000 p. 650). According to this definition, psychological measurement simply involves the systematic application of predefined instructions for allocating numerals to objects or events: for example, always attaching the number ' 5 ' to the Likert scale option "very much like me". This superficially reasonable procedure actually means that instruments such as the VIA test can seemingly "achieve measurement without needing to investigate the issue of whether psychological attributes are quantitative" (Michell, 2008 p. 9). This leads to a situation where "the hazard of educational and psychological measurement is that almost anyone can devise his or her own set of rules to assign some numbers to some subjects" (Suen, 1990 p. 5). Historically, UK education policy provides a notorious example of the consequences of applying this kind of ad-hoc flexibility, when an intelligence test called the '11-plus' 
[p.8] was used to 'grade' children's ability and assign them to schools - secondary modern or grammar - offering different levels of education. That the policy has since been shown to rest upon data that were falsified (Hearnshaw, 1979) only adds to the irony that the inventor of the first such test, Binet, explicitly warned that any use of intelligence tests to rank or grade individuals would be illegitimate (Rose et al., 1984).

Finally, there is the issue of personal meaning. Rating scales (such as the 5-point Likert scale used by the VIA test) require participants to introspect so as to provide a numerical estimate of an assumed 'degree' of some characteristic along a linear scale. Superficially, this might appear to be an objective process of quantification, but Rosenbaum and Valsiner (2011) demonstrate that the massively different constellations of personal meaning that people bring to the testing situation remain influential when people complete rating scales. Using a well-established personality test, the highly-regarded and widely used NEO-PI (Costa and McCrae, 1992), they asked participants to write down their interpretations of the meaning of the opposing end points of the scale as they made their ratings. Far from having the same meaning for everyone, this procedure revealed that different participants attached very different meanings to the scale points: in other words, that ostensibly the same mark on the scale actually meant quite different things to each participant. This finding suggests [p.9] that the rating process used in the VIA test is "not a neutral one-to-one medium between the researcher and the participant" (Rosenbaum and Valsiner, 2011 p. 61). Both the questions and the scale on which the rating is marked will be actively interpreted and evaluated by benefit claimants, and so "it is a misplaced assumption that participants have direct access to their response and that this response is static and can be represented as a mark along a line .. rating scale data, despite being statistically manipulated, should not (and indeed cannot) be thought of as objective" (ibid.).

In sum, there are multiple reasons to be sceptical about the neutrality and accuracy of the VIA test: these include concerns about validity and response bias, problems associated with introspection, and more fundamental problems associated with the method of measurement and the use of rating scales. Many of these issues alone would be sufficient to make us question BIT's presentation of the VIA test as though it were a straightforwardly objective measure; taken together, they begin to show how:

The contribution of psychometric modelling is fundamentally a political one, as it permits the assimilation of the reality of phenomena that are described in a qualitative way and can at best be partially ordered to an intuitively totally ordered reality, where the social utility rests on the need for comparison of human beings. (Vautier et al., 2012 p. 818)

\section{The VIA test}

So, psychometric tests of personality and character may not be as objective, accurate or insightful as their advocates would like, and this may compromise their suitability as neutral instruments of policy. If we nevertheless presume that the VIA test can and does measure something meaningful about the individuals who take it, further questions remain. For example, whilst ethical issues are not our primary focus, aspects of this initiative may be seen as contrary to the ethical code of the 
British Psychological Society (BPS, 2009), the professional body which regulates psychological testing in the UK. The Society's ethical code emphasises respect, competence, responsibility and integrity, with respect to concrete issues including informed consent, the right to withdraw, anonymity and confidentiality. Arguably, informed consent is compromised by BIT's presentation of the test as though it were part of a larger online test library, when in fact it seems to have been specifically set up for this policy; the use of benefit sanctions to compel claimants to take the test challenges both informed consent and the right to withdraw; and the instruction to email results to benefits advisers seems to disregard confidentiality and anonymity. Concerns about competence and integrity might also [p.10] be raised since the policy deploys a test that, seemingly, was already known to be invalid.

Moreover, once we look more closely at the VIA test itself yet more concerns become apparent. Many of these concerns can ultimately be traced back to the points of more general criticism of psychometric testing that were outlined above. As we have seen, the VIA test consists of forty-eight prompts to which participants respond using a 5-point Likert scale. However, despite the potentials for quantification that this procedure yields, no numerical scores are produced: instead, a textual profile of 'signature strengths' is generated. In each case the profile consists of just five strengths; Table 1 shows how some of these strengths are described.

[Table 1 near here]

A first question is precisely how such a textual profile might actually assist benefit claimants: if the BIT policy is designed to help people off benefits and into employment, exactly how might it do so? Rather than assessing any kind of capability or capacity, the VIA test claims to assess character. In so doing it ignores aptitude, knowledge, experience and transferrable skills: all attributes with far more obvious relevance to employment potentials. What is more, to the extent that knowledge of signature strengths might nevertheless be considered useful, it is difficult to see how such brief, superficial and very general descriptions as those in Table 1 could be of great value. We nevertheless suggest that there is a deeper, latent logic by which the VIA test is both meaningful and functional, a logic that presumes and replicates the neoliberal ideology that currently shapes UK welfare policy and provision. We will demonstrate this by examining the VIA test in more detail, looking first at its context and mode of administration and then at its results.

\section{Context and Mode of Administration}

The context, it will be recalled, is that some benefit claimants seem to have been required to take this test or face the sanction of having their benefits cut. This requirement arises in a broader social context where claimants have been demonised by politicians and media as 'skivers' and 'scroungers', and in the policy context of an increasingly punitive benefits regime. The immediate, specific context of the requirement to take the test is further shaped by written advice that "When applying for jobs it is important to emphasise your strengths and abilities ...This exercise has been scientifically shown to find people's strengths" (skwalker1964, 2013). Other elements of context are only supplied when the test is completed and the results are displayed. At the top of the results screen claimants are advised to "Think about how you can use these strengths in your job search and in your life in general. Try to find a new way to use them then (sic) everyday." Below the results is another instruction which asks claimants to "Fill in your email address below to have your strengths emailed to you. You may want to discuss these with your advisor at [p.11] your next meeting." 
According to (skwalker1964, 2013), further instructions are then dispensed, including the advice to "aim to use each of your strengths in a new way everyday (sic) for at least a week."

It is clear that there is a coercive power relation at play here: if you do not take this test you may not receive your benefits. However, we want to suggest that other more subtle power relations permeate the entire procedure and are, in fact, crucial to an understanding of its logic. Foucault's (2008) analysis of neoliberalism highlighted the way in which it represents a reconfiguration of human nature and the social order in accord with the dictates and demands of the market, and that in so doing it implied a new kind of subject. It is in this sense a particular instance of governmentality, i.e. "a particular mentality, a particular manner of governing, that is actualised in habits, perceptions and subjectivity" (Read, 2009 p.34). Neoliberalism, then, implies a technology of the self (Foucault, 1988), a mode of subjectification, in the double sense of both being subjected to a power relation and, in so doing, working to reflexively understand one's self as a particular kind of subject.

Understood as a technology of the self, the context of administration of the VIA test takes on a new significance. Alongside the explicit coercion of the threatened benefits sanction there are explicit injunctions to work on the self: by thinking about how to use the strengths the test identifies, and trying to use these strengths 'everyday'. Scholars who have analysed neoliberal subjectivities frequently highlight the emphasis that neoliberalism places on personal responsibility. We see this emphasis enacted here, not only in the (forced) responsibility to take the test, but also in the further responsibility to work on the self in light of its results. In this regard it is also notable how the textual descriptions of the signature strengths are saturated with second-person imperatives: throughout, the authors directly address 'you', they consistently make 'you' responsible for being the kind of person 'you' are.

Other aspects of this technology of the self are associated with the momentary psychological significances of the actual practice of taking the VIA test. Stenner and Taylor (2008) observe that psychology supplies policy with texts and narratives of identity that are authoritative and influential precisely because of their ostensibly 'scientific' character. Those benefit claimants who are largely unused to psychological practices might be somewhat dazzled by this aura of expertise, and so persuaded that the test will reveal deeply meaningful and perhaps previously hidden personal truths. Further significances may flow from the expenditure of time and effort necessarily entailed in taking the test: effortful engagement with practice tends to increase its meaning and perceived value (Marshall, 2002), so might enhance the apparent significance of the results the test generates. An additional, more subtle but no less significant psychological effect arises because, in the process of completing the test, participants necessarily objectify themselves. They must momentarily take their own selves as objects of reflection, seeing [p.12] themselves as (they imagine) others see them, and in this moment of perspectival doubling they actually rehearse the very practice of remaking the self that neoliberal governmentality demands.

\section{Results}

To sample the range of strengths profiles generated by the test, we completed it ten times. In the first iteration ('paragon') we selected what we judged to be the most socially desirable answer to every question; in the second ('sociopath') we did the exact opposite and tried to present ourselves in the worst possible light. For the next three iterations we selected either 'neutral', 'very much like 
me', or 'very much unlike me', respectively, in response to every question. Then, for the next five iterations we used different quasi-random patterns of answers: that is, we systematically varied the sequences we gave (e.g. by moving in order from 'very much like me' to 'very much unlike me' and then back again). This procedure generated five patterns of answers, each different from the other, and each random with respect to the meanings of the forty-eight questions. Although this procedure did not cover more than a fraction of the many different ways in which the test could be completed, it was sufficient to generate a representative sample of the profiles it generates: these are summarised in Table 2.

[Table 2 near here].

As Table 2 shows, despite the differences between each of these iterations, many of the ten profiles were remarkably similar, and three - paragon, neutral, very much unlike me - were identical. This finding perhaps lends weight to VIA's objection that this version of the test had failed validity checking and should not have been used. In total, fifteen different signature strengths were identified in our ten iterations: however, six of these appeared only once, and another four appeared only twice. Conversely, the five strengths listed in Table 1 all recurred frequently: each of the first three of these - curiosity, love of learning and critical thinking - appeared on eight different profiles, and all three appeared together on six profiles. Of the other two strengths in Table 1, social intelligence appeared on seven profiles and originality on five.

We then examined the content of these five recurring character strengths, and found that we could readily identify three interwoven themes. The first theme can be characterised as rationality: someone with these attributes asks questions, enjoys learning, and carefully evaluates every situation; when making decisions this person does not jump to conclusions but instead considers only 'solid evidence' to make decisions. We have described Whitehead et al.'s (2011) finding that previous UK policy implementations of behavioural economics have tended to emphasise or prioritise rationality, even though a distinctive feature of the literature is its acknowledgement that decision-making - whether characterised as good or as bad - is always felt or emotive as [p.14] well as rational or discursive. They observed that by interpreting behavioural economic precepts in this way, UK policy makers have tended to associate emotionality primarily with problematic choices and groups. On the basis of these profiles it seems that this policy initiative by BIT might illustrate a similar or related tendency, an attempt to foster and promote rationality amongst benefit claimants who - presumably, therefore - are thought to lack these qualities.

The second theme relates to flexibility: the person with these strengths is curious, enjoys exploration and discovery, takes opportunities to learn, adapts to the feelings and positions of others, and is able to change her or his mind. In the literature on neoliberal subjectivities, flexibility is a prominent and recurrent theme. Neoliberal initiatives restructure employment by promoting casualization and precarity, ending 'jobs for life' and discursively positioning workers as vendors of their own portfolio of ability and experience. Workers must become self-sufficient entrepreneurs, individuals who voluntarily engage in personal 'branding' and its associated immaterial labour: for example, by developing appropriate online personae and marketing particular transferable skills (Hearn, 2008). Hence, flexibility becomes a vital personal quality, since workers must be constantly prepared to seize opportunities, develop skills, and apply their competencies in new situations 
The third theme can be described as innovation: these strengths suggest a person who seeks out new ideas, can take up new positions, and is ready to defy convention in order to develop new ways of working. This theme is closely related to the previous one, since the capacity to innovate is closely associated with the ability to be flexible. Innovation extends flexibility in relation to agency and leadership: not only can the person change, the person can initiate change. She or he is not merely flexibly responsive to demands, but is also a 'change agent' - one who initiates change. The notion of the change agent is well established as a popular trope in business and management texts (e.g. Carr et al., 1996), where it refers to people who apply entrepreneurial vision and direction to themselves and their situation in order to promote beneficial outcomes in fields such as education (Fullan, 1993), community health (Eng and Young, 1992) and, of course, business and finance (Tanner-Pascale and Sternin, 2005).

Whilst the content of these five recurring signature strengths is interesting in itself, this frequently recurring profile may also be significant for what it omits. In a context where benefit claimants have been demonised by government ministers, the test's frequent endorsement of this particular set of qualities - and concomitant neglect of others - might help promote docile acceptance of the social position currently being carved out for claimants. The positive psychology taxonomy of character strengths and virtues, from which these 'signature strengths' are derived, includes both "Bravery: Not shrinking from threat, challenge, difficulty, or pain; speaking up for what [p.15] is right even if there is opposition; acting on convictions even if unpopular; includes physical bravery but is not limited to it" and "Fairness: Treating all people the same according to notions of fairness and justice; not letting personal feelings bias decisions about others; giving everyone a fair chance" (VIA, 2004). Bravery could readily be associated with the pursuit of equality, or determined attempts to challenge prejudice and achieve social justice: but this strength did not appear within any of the ten profiles we generated. Fairness was generated by two profiles; however, whilst the original wording explicitly refers to notions of justice the test version entirely omits this reference, saying only that: "Treating all people fairly is one of your abiding principles. You do not let your personal feelings bias your decisions about other people. You give everyone a chance". Here, fairness is solely confined to individual principles, personal feelings, and interpersonal decisions about others. There is no mention of justice, no suggestion that wider social relations, structures and processes might also be relevant to equitable outcomes. The VIA test wording converges with a restrictive 'morality of fairness' within which benefit claimants are positioned as undeserving burdens upon their hard working peers, in comparison with whom they have no legitimate claim to fair treatment (Clarke and Newman, 2012).

Of course, the themes we identified do not exhaust all of the capacities proscribed by these five recurring signature strengths. For example, the notion of social intelligence, with its emphasis on being aware of and responsive to the feelings of others, is not immediately consonant with most descriptions of neoliberal subjectivity that we have seen (although its exhortation that "you know what to do to put other people at ease" might be seen as endorsing aspects of the affective labour closely associated with Western contemporary capitalism - Hardt, 1999). Subjectivities are fluid, variegated, contradictory and mobile, and the technologies by which they are assessed and regulated never perfectly capture their dynamisms and potentials - there is always an excess (Stephenson and Papadopoulos, 2007). Nevertheless, our conclusion is that the likely effect of this initiative is to nudge benefit claimants toward the adoption and rehearsal of key aspects of neoliberal subjectivities, to inflect the discursive networks within which their subjectivities are 
formed with a particular constellation of qualities, and so to help inculcate a collective self-image characterised by the relations to self and others that are demanded by a precarious labour market dominated by financial and service industries.

\section{Conclusion}

It would be naïve to imagine that the majority of those benefit claimants who took this test were profoundly influenced - either by the procedure, [p.16] or by the profile it generated. We should not presume that most claimants answered the questions seriously, or that they inevitably attached great significance to the results. Nevertheless, with more than 1.5 million people currently claiming Jobseekers Allowance, and another million not working but ineligible to claim (ONS, 2013), only small percentages need to have been influenced for this initiative to affect many thousands of people. In this way, the VIA test policy resembles other relatively cheap yet wide-ranging initiatives implemented by BIT, such as small changes to the wordings of letters being sent to fine defaulters and people owing tax (BIT, 2012).

Importantly, we are not claiming that BIT is responsible for a knowing conspiracy whereby selectively identified features of neoliberal subjectivities are being coercively promoted to benefit claimants. There is no evidence that either BIT or VIA deliberately weighted the test to make the profiles it generates accord more closely with the subjectivities that neoliberalism requires: indeed, it seems more likely that something far more banal (and banally significant) has occurred. We suspect that the frequently recurring profiles of strengths - generated by the VIA test, and endorsed by BIT's uncritical use of them as instruments of policy - simply reflect the prevalence within both organisations of unexamined presumptions with regard to notions of the worthwhile citizen, the good employee, the diligent jobseeker, and the deserving recipient of benefit. These presumptions will have shaped the items selected for the test; the ways the items were worded; the ways the items were scored; the ways the scores were summed or averaged; the ways those sums or averages were associated with different character strengths; the ways that people were selected and stratified in studies designed to validate the test; the wordings of the textual descriptions of the character strengths, and so on. In short: the presumptions shared by VIA and by BIT simply demonstrate that neoliberal precepts form part of the taken for granted common-sense of both organisations: hence, no conspiracy need be posited in order to understand the many correspondences between the outcomes of the VIA test and the requirements of this ideology.

Ideology, of course, is an important element of power. Regardless of the claims of benevolent libertarian paternalism made by behavioural economics, BIT's use of the VIA test illustrates how power can be wielded and transmitted in a precarious labour market, through a stigmatised, stigmatising and punitive welfare system, to induce claimants to work on themselves in ways consonant with the ruling ideology of our time. Like all ideologies, neoliberalism is unfinished: it exists in a field of contestation with other ideologies, other possible worlds and other possible selves. The BIT initiative is one means by which this ideological contestation is being drilled down to the most intimate psychological level of individual experience. 


\begin{tabular}{|l|l|}
\hline Curiosity & $\begin{array}{l}\text { You are curious about everything. You are always asking questions, and you } \\
\text { find all subjects and topics fascinating. You like exploration and discovery }\end{array}$ \\
\hline Love of Learning & $\begin{array}{l}\text { You love learning new things, whether in a class or on your own. You have } \\
\text { always loved school reading and museums - anywhere and everywhere there } \\
\text { is an opportunity to learn }\end{array}$ \\
\hline Critical thinking & $\begin{array}{l}\text { Thinking things through and examining them from all sides are important } \\
\text { aspects of who you are. You do not jump to conclusions, and you rely only on } \\
\text { solid evidence to make your decisions. You are able to change your mind }\end{array}$ \\
\hline Social Intelligence & $\begin{array}{l}\text { You are aware of the motives and feelings of other people. You know what to } \\
\text { do to fit into different social situations, and you know what to do to put } \\
\text { others at ease. }\end{array}$ \\
\hline Originality & $\begin{array}{l}\text { Thinking of new ways to do things is a crucial part of who you are. You are } \\
\text { never content with doing something the conventional way if a better way is } \\
\text { possible. }\end{array}$ \\
\hline
\end{tabular}

Table 1: descriptions of 'signature strengths' generated by the test 


\begin{tabular}{|c|c|c|c|c|c|c|c|c|c|c|}
\hline & Paragon & Sociopath & Neutral & Like Me & Unlike Me & Random 1 & Random 2 & Random 3 & Random 4 & Random 5 \\
\hline Curiosity & $\mathrm{x}$ & $\mathrm{x}$ & $\mathrm{x}$ & $\mathrm{x}$ & $\mathrm{x}$ & & $\mathrm{x}$ & & $\mathrm{x}$ & $\mathrm{x}$ \\
\hline Love of Learning & $\mathrm{x}$ & $\mathrm{x}$ & $\mathrm{x}$ & $\mathrm{x}$ & $\mathrm{x}$ & & $\mathrm{x}$ & & $\mathrm{x}$ & $\mathrm{x}$ \\
\hline Critical Thinking & $x$ & $x$ & $x$ & $x$ & $x$ & $x$ & & $x$ & & $x$ \\
\hline Social Intelligence & $x$ & & $x$ & & $x$ & & $x$ & $x$ & $x$ & $x$ \\
\hline Originality & $x$ & & $x$ & $\mathrm{x}$ & $x$ & & & & $x$ & \\
\hline Carefulness & & $x$ & & & & & & & & \\
\hline Humour & & & & & & $\mathrm{x}$ & & & & \\
\hline Kindness & & & & $x$ & & & & & & \\
\hline Fairness & & & & & & $x$ & & & & $x$ \\
\hline Dedication & & & & & & $x$ & & $x$ & & \\
\hline Honesty & & & & & & & $x$ & $x$ & & \\
\hline Loving & & & & & & & & $x$ & & \\
\hline Perspective & & & & & & & $x$ & & $x$ & \\
\hline Modesty & & $x$ & & & & & & & & \\
\hline Appreciation of Culture & & & & & & $x$ & & & & \\
\hline
\end{tabular}

Table 2: profiles of signature strengths generated by different test strategies 


\section{REFERENCES}

Becker D and Marecek J. (2008) Dreaming the American Dream: individualism and positive psychology. Social and Personality Psychology Compass 2: 1767-1780.

BIT. (2012) Applying behavioural insights to reduce fraud, error and debt.

BPS. (2009) Code of Ethics and Conduct. Leicester: The British Psychological Society.

Brown W. (2006) American Nightmare: neoliberalism, neoconservatism and de-democratisation. Political Theory 34: 690-714.

Carr D, Hard K and Trahant W. (1996) Managing the change process: A field book for change agents, consultants, team leaders, and reengineering managers, New York: McGraw Hill.

Christopher J and Hickinbottom S. (2008) Positive Psychology, Ethnocentrism and the Disguised Ideology of Individualism. Theory and Psychology 18: 563-589.

Clarke J and Newman J. (2012) The alchemy of austerity. Critical Social Policy 32: 299-319.

Coote A and Lyall S. (2013) Strivers v skivers: real life's not like that at all. The Guardian. London.

Costa P and McCrae R. (1992) NEO PI-R Professional Manual, Odessa, FL: Psychological Assessment Resources Inc.

AUTHOR (2011)

Danziger K. (1994) Constructing the Subject: historical origins of psychological research, Cambridge: Cambridge University Press.

Ehrenreich B. (2009) Smile or Die: how positive thinking fooled America and the world, London: Granta.

Eng E and Young R. (1992) Lay health advisors as community change agents. Family and Community Health 15: 24-40.

Essex C and Smythe W. (1999) Between numbers and notions: A critique of psychological measurement. Theory and Psychology 9: 739-767.

Foucault M. (1988) Technologies of the self. In: Martin L, Gutman H and Hutton P (eds) Technologies of the Self. London: Tavistock Publications, 16-49.

Foucault M. (2008) The Birth of Biopolitics: Lectures at the Collège de France, 1978-1979, Basingstoke: Palgrave Macmillan.

Fullan M. (1993) Why Teachers Must Become Change Agents. Educational Leadership 50: 12-17.

Fyson, R \& Cromby, J. (2012) 'Human Rights and Intellectual Disabilities in an Era of "Choice"', Journal of Intellectual Disability Research, doi: 10.1111/j.1365-2788.2012.01641.x

Hardt M. (1999) Affective Labour. Boundary 2 26: 89-100.

Hearn A. (2008) Variations on the Branded Self: theme, invention, improvisation and inventory. In: Hesmondhalgh D and Toynbee J (eds) The Media and Social Theory. London: Routledge, 194210.

Hearnshaw LS. (1979) Cyril Burt, Psychologist, Ithica: Cornell University Press.

Held B. (2005) The'Virtues' of Positive Psychology. Journal of Theoretical and Philosophical Psychology 25: 1-34.

Jackson SL. (2012) Research methods and statistics: A critical thinking approach, Belmont, CA.: Wadsworth.

Kahneman D and Tversky A. (1982) Judgement Under Uncertainty: heuristics and biases. Cambridge: Cambridge University Press.

Malik S. (2013) Jobseekers' psychometric test 'is a failure'. The Guardian. London.

Marshall D. (2002) Behaviour, Belief and Belonging: a theory of ritual practice. Sociological Theory 20: $360-380$.

Michell J. (2000) Normal Science, Pathological Science and Psychometrics. Theory and Psychology 10: 639-667.

Michell J. (2008) Is Psychometrics Pathological Science? Measurement: Interdisciplinary Research and Perspectives 6: 7-24.

Mulheirn I. (2013) The myth of the "welfare scrounger". New Statesman. London.

ONS. (2013) Labour Market Statistics May 2013. (accessed 23/5/2013). 
Papadopoulos D. (2003) The Ordinary Superstition of Subjectivity: liberalism and technostructural violence. Theory and Psychology 13: 73-93.

Peck J and Tickell A. (2002) Neoliberalizing Space Antipode 34: 380-404.

Peterson C and Seligman M. (2004) Character Strengths and Virtues: a handbook and classification, New York: Oxford University Press.

Prideaux S. (2010) The Welfare Politics of Charles Murray are alive and well in the UK. International Journal of Social Welfare 19: 293-302.

Read J. (2009) A Genealogy of Homo-Economicus: Neoliberalism and the Production of Subjectivity. Foucault Studies 6: 25-36.

Robins FW, Fraley RC and Krueger RF. (2007) Handbook of Research Methods in Personality Psychology, New York: Guilford Press.

Rose S, Lewontin R and Kamin I. (1984) Not in Our Genes, Harmondsworth: Penguin.

Rosenbaum P and Valsiner J. (2011) The un-making of a method: From rating scales to the study of psychological processes. Theory and Psychology 21: 47-65.

Rust J and Golombok S. (1999) Modery Psychometrics: the science of psychological assessment, London: Routledge.

Seligman M. (2003) Authentic Happiness, London: Nicholas Brealey Publishing.

skwalker1964. (2013) A Tale of Two Maggies. Available at: http://skwalker1964.wordpress.com/2013/04/17/a-tale-of-two-maggies/.

Slife B and Richardson F. (2008) Problematic Ontological Underpinnings of Positive Psychology: a strong relational alternative. Theory and Psychology 18: 699-723.

Stenner P and Taylor D. (2008) Psychosocial welfare: Reflections on an emerging field. Critical Social Policy 28: 415-437.

Stephenson N and Papadopoulos D. (2007) Analysing Everyday Experience: social research and political change, London: Palgrave Macmillan.

Suen HK. (1990) Principles of Test Theories, Hillsdale NJ: Lawrence Erlbaum Associates.

Tanner-Pascale R and Sternin J. (2005) Your Company's Secret Change Agents. Harvard Business Review: 1-10.

Thaler R and Sunstein C. (2009) Nudge: Improving Decisions About Health, Wealth and Happiness, London: Penguin.

Vautier S, Veldhuis M, Lacot E, et al. (2012) The ambiguous utility of psychometrics for the interpretative foundation of socially relevant avatars. Theory and Psychology 22: 810-822.

VIA. (2004) The VIA Classification of Character Strengths. (accessed 23/5/2013).

Weiten W. (2010) Psychology: Themes and variations, Belmont CA.: Wadsworth.

Whitehead M, Jones R and Pykett J. (2011) Governing irrationality, or a more than rational government? Reflections on the rescientisation of decision making in British public policy. Environment and Planning A 43: 2819-2837.

Wiggan J. (2012) Telling stories of 21st century welfare: The UK Coalition government and the neoliberal discourse of worklessness and dependency. Critical Social Policy 32: 383-405.

Wilson T and Hodges S. (1992) Atttitudes as Temporary Constructions. In: Martin L and Tesser A (eds) The Construction of Social Judgments. Hillsdale NJ: Lawrence Erlbaum Associates, 3765.

Yen J. (2010) Authorizing Happiness: rhetorical demarcation of science and society in historical narratives of positive psychology. Journal of Theoretical and Philosophical Psychology 30: 6778. 